\title{
DORES E DELÍCIAS DA PESCA ARTESANAL: UM OLHAR PARA A INFLUÊNCIA DO MEIO AMBIENTE NO TRABALHO E NA SAÚDE
}

\section{PAINS AND DELIGHTS OF HOMEMADE FISHING: A LOOK TO THE ENVIRONMENT INFLUENCE AT WORK AND HEALT}

\author{
Camila Martins de Oliveira ${ }^{1}$, Karollinne Giovannda de Sousa Viana ${ }^{2}$, Taciane Correia dos \\ Santos $^{3}$, Dário da Silva Mota ${ }^{4}$, Maria Jacqueline Santana Melo da Costa ${ }^{5}$, Francisco \\ Rosemiro Guimarães Ximenes Neto ${ }^{6}$ \\ ${ }^{1}$ Universidade Estadual Vale do Acaraú, Sobral, Ceará, Brasil/Graduada do Curso de Enfermagem. E- \\ mail: martinscamila75@gmail.com \\ ${ }^{2}$ Universidade Estadual Vale do Acaraú, Sobral, Ceará, Brasil/Graduada do Curso de Enfermagem. E- \\ mail: karollviana33@gmail.com \\ ${ }^{3}$ Universidade Estadual Vale do Acaraú, Sobral, Ceará, Brasil/Graduada do Curso de Enfermagem. E- \\ mail: taciane00@hotmail.com \\ ${ }^{4}$ Universidade Estadual Vale do Acaraú, Sobral, Ceará, Brasil/Graduado do Curso de Enfermagem. E- \\ mail:dmota29@gmail.com \\ ${ }^{5}$ Universidade Estadual Vale do Acaraú, Sobral, Ceará, Brasil/Graduada do Curso de Enfermagem. E- \\ mail: kelly_mell21@hotmail.com \\ ${ }^{6}$ Universidade Estadual Vale do Acaraú, Sobral, Ceará, Brasil/Docente do Curso de Enfermagem do \\ Centro de Ciências da Saúde. E-mail: rosemironeto@gmail.com
}

\section{RESUMO}

O pescador artesanal é aquele que exerce a pesca com fins comerciais, de forma autônoma ou em regime de economia familiar, com meios de produção próprios ou mediante contrato de parcerias. Em seu dia a dia, os pescadores estão envoltos a diversos determinantes que interagem com meio ambiente-saúde-trabalho e podem vulnerabilizá-los, deixando-os expostos a riscos, doenças e agravos ocupacionais. Este estudo tem como objetivo descrever a influência do meio ambiente no trabalho e na saúde de pescadores artesanais e os riscos ocupacionais a que estes estão submetidos. Estudo descritivo, sob abordagem qualitativa, realizado durante os meses de março a julho do ano de 2014, tendo como sujeitos um ex-pescador, o dono de uma pesqueira e pescadores. A coleta das informações se deu por meio da observação participante, memorial fotográfico do processo de trabalho, entrevista semiestruturada e diário de campo. A análise das informações se pautou no referencial da análise temática de Minayo, que deu origem a três categorias temáticas: Resgate da historicidade do trabalho; Dores da pesca artesanal: relação com o meio ambiente e saúde; Delícias da pesca artesanal: a satisfação do fazer e do ser pescador. Os pescadores artesanais apresentaram como dores do trabalho, o desenvolvimento de doenças ocupacionais e, delícias do trabalho, os sentimentos de satisfação, liberdade e vocação. Observou-se a necessidade do estabelecimento de políticas públicas voltadas para estes trabalhadores, visando reduzir os riscos e os danos causados à saúde, devido ao exercício da profissão e, que melhorem a qualidade de vida destes.

Palavras-Chave: Meio Ambiente, Saúde do Trabalhador, Doenças do Trabalho. 


\begin{abstract}
The angler craft is one that has fishing for commercial purposes, independently or in the household economy, with means of production themselves or via a contract of partnerships. In their day-to-day, fishermen are wrapped in various determinants that interact with the environment-health-work and can to make them vulnerable, leaving them exposed to risks, diseases and occupational health problems. This study aims to describe the influence of environment at work and on the health of artisanal fishermen and the occupational risks to which they are subjected. A descriptive study, under a qualitative approach, carried out during the months of March to July of the year of 2014, having as subject a former fisherman, the owner of a fisheries and fishermen. The collection of information was through participant observation, photo memorial of the work process, interviews and field journal. The analysis of the information that has no reference of thematic analysis of Minayo, which gave rise to three thematic categories: Rescue the historicity of labor; Pains of artisanal fishing: relationship with the environment and health; delicacies of artisanal fishing: the satisfaction of doing and being a fisherman. The artisanal fishermen had as pangs of labor, the development of occupational diseases, and delights of the work, the feelings of satisfaction, freedom and vocation.
\end{abstract}

Key words: Environment, Occupational Health, Occupational Diseases.

\title{
INTRODUÇÃO
}

A pesca é uma das atividades produtivas mais antigas da humanidade, tendo sido a base da economia e fonte de sobrevivência de diversas civilizações. Segundo dados do Ministério da Pesca e Aquicultura, no Brasil existem 970 mil pescadores registrados, destes 957 mil são pescadores artesanais (BRASIL, 2011). Já o estado do Ceará possui 76 colônias de pescadores artesanais, apresentando um contingente, segundo a Secretaria da Pesca e Aquicultura do Estado de 55.000 trabalhadores, que sobrevivem da atividade pesqueira (CEARÁ, 2014).

O pescador artesanal é aquele que exerce a pesca com fins comerciais, de forma autônoma ou em regime de economia familiar, com meios de produção próprios ou mediante contrato de parcerias, desembarcada ou com embarcações de pequeno porte, devidamente licenciado pelo Ministério da Pesca e Aquicultura (BRASIL, 2011). O pescador é um profissional que tem seu trabalho diretamente relacionado ao meio ambiente, onde exerce sua função sob condições precárias, com elevada carga de trabalho, associada a baixos salários e está constantemente exposto a riscos à sua saúde (MONTEIRO, 2007).

Dessa forma, a saúde ambiental, nas últimas décadas, está sendo vista como um conjunto de condutas voltadas para a preservação do meio ambiente, também para a compreensão da realidade dos problemas que direta ou indiretamente o afetam, sendo 
item norteador de ética nas relações sociais, relações estas que se desdobram também, em relações de trabalho, como a atividade pesqueira (MORADILIO; OKI, 2004).

A relevância desse tema está relacionada aos aspectos ambientais que afetam o processo saúde-doença-cuidado, o que evidencia as relações entre meio ambiente-saúdetrabalho, e se constituem, preponderantes para a construção de discursos e práticas que possam nortear o pensar e o agir dos profissionais da saúde.

Diante dessa realidade, surgiu o interesse de se identificar os aspectos relacionados ao meio ambiente, trabalho e saúde envolvidos na pesca artesanal, por esta ser uma atividade tradicional no Brasil, em especial ao Estado do Ceará e, ao mesmo tempo tão pouco estudada. Assim, este estudo teve como objetivo descrever a influência do meio ambiente no trabalho e na saúde de pescadores artesanais e os riscos ocupacionais aos quais estes estão submetidos.

\section{RELAÇÃO MEIO AMBIENTE, TRABALHO E SAÚDE}

O meio ambiente é um conjunto de relações entre os seres vivos e os seres não vivos. Com o decorrer dos tempos, a ciência evoluiu e os fenômenos naturais começaram a ser compreendidos, a natureza passou a ter uma relação de interdependência em relação à espécie humana. Consequentemente, começou a haver um maior conhecimento do ambiente e uma maior exploração dos seus recursos. Dessa forma, a influencia ambiental na vida humana e vice-versa, não deve ser tratada com neutralidade, pois, é necessário entender que esta pode transformar a relação da sociedade, com o seu trabalho e saúde (BAUM; POVALUK, 2012).

Vargas e Oliveira (2007) corroboram com tal contexto, ao afirmarem que o meio ambiente é uma produção social que pode influenciar o trabalho e sobretudo à saúde humana, de maneira individual ou coletiva, direta ou indiretamente, o que torna a relação entre saúde, trabalho e meio ambiente uma complexa relação, entre natureza e

sociedade. É dessa relação marcada por grandes contradições que surgem os riscos ambientais, considerados entre os grandes problemas da Saúde Pública e Saúde Coletiva hoje, já que afetam a qualidade de vida da população e, consequentemente, sua saúde.

Contudo, o meio ambiente exerce influência direta e indireta no processo saúde e doença. Dessa forma, observa-se no modelo de Determinantes Sociais da Saúde proposto por Dahlgren e Whitehead (1991) cinco níveis interdependentes, que atuam sobre o processo saúde-doença de grupos e indivíduos. Este modelo é dividido por macrodeterminantes e microdeterminantes. 
O nível mais externo deste modelo revela os macrodeterminantes representados pelas condições socioeconômicas, culturais e também ambientais gerais; no nível subsequente os determinantes intermediários como as condições de vida e de trabalho. A compreensão do processo saúde-doença decorre da análise dos micro e macro determinantes e suas formas de correlação e mediação, atribuindo a influência ambiental e das condições de trabalho no contexto da saúde (CASTELLANOS, 1997).

Figura 1: Modelo de Determinantes Sociais da Saúde, segundo Dalhgren e Whitehead (1991).

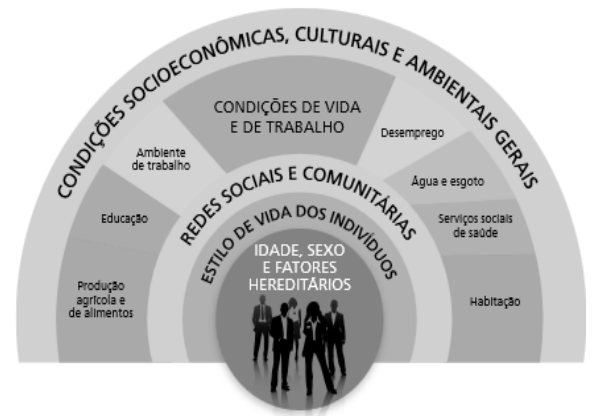

Fonte: Adaptado pela Comissão Nacional sobre Determinantes Sociais da Saúde (2008).

Em relação a Promoção da Saúde direcionada a questão do meio ambiente, a Carta de Otawa traz sugestões de condições mínimas para a saúde, entre elas a sustentabilidade do ecossistema e a criação de ambientes favoráveis à saúde (BRASIL, 2001).

\section{METODOLOGIA}

Esta pesquisa, trata-se de um estudo descritivo, sob abordagem qualitativa, realizado durante os meses de março a julho do ano de 2014. Apoiando-se no referencial de Minayo (2014), em que a abordagem qualitativa se conforma na investigação de grupos e segmentos delimitados e focalizados, de histórias sociais sob a ótica dos atores, de relações e para análises de discursos e de documentos, pois permite desvelar processos sociais, ainda pouco conhecidos referentes a grupos particulares, propicia à construção de novas abordagens, revisão e criação de novos conceitos e categorias durante a investigação.

O cenário da investigação foi a cidade de Camocim, que fica localizada na microrregião do Litoral de Camocim e Acaraú, mesorregião do Noroeste Cearense, a $365 \mathrm{~km}$ da capital Fortaleza (BRASIL, 2011b). Os sujeitos do estudo foram um ex- 
pescador, com experiência tanto na pesca artesanal, quanto na pesca industrial e o dono de uma pesqueira de médio porte; sendo os pescadores sujeitos da observação.

Para a coleta das informações foram realizadas entrevistas semiestruturadas, com questões voltadas a percepção e vivências dos sujeitos em relação ao seu trabalho, ao meio ao qual estão inseridos e as suas repercussões para a saúde. Utilizou-se como forma de registro das informações o gravador para as entrevistas, o diário de campo, e a confecção de um memorial fotográfico do processo de trabalho.

Também como forma de coleta das informações, utilizou-se a observação participante de maneira que, a imersão dos pesquisadores no cenário de trabalho dos pescadores, permitiu a oportunidade de compreender de modo prático as implicações que o meio ambiente pode determinar na saúde dos sujeitos, de modo que a experiência extra universidade foi uma ferramenta de aproximação possível da realidade.

Depois de concluída a fase de coleta das informações, iniciou-se o processo de sistematização e análise destas, com a transcrição das entrevistas, posteriormente, fez-se uma leitura vertical de cada, logo após, uma leitura horizontal do conjunto. A análise das informações se pautou no referencial de Minayo (2014) de análise temática, subdivido nas seguintes fases: Pré-análise, Exploração do Material e Tratamento dos Resultados Obtidos e Interpretação. As informações foram organizadas procurando reunir e destacar as tendências e padrões relevantes presentes no seu conteúdo.

Em seguida, realizou-se a categorização temática das informações, retirando das entrevistas transcritas as palavras, frases, expressões significativas e os temas que considerados relevantes foram discutidos. Originaram-se três categorias temáticas: Resgate da historicidade do trabalho; Dores da pesca artesanal: relação com o meio ambiente e saúde; Delícias da pesca artesanal: a satisfação do fazer e do ser pescador.

Posteriormente a análise das informações, apresentou-se em forma de seminário e discutiu-se em sala de aula, com os demais acadêmicos as implicações e percepções advindas deste estudo. Neste contexto, a universidade possui um papel de instituição fomentadora e formadora de profissionais críticos-reflexivos, por ser um espaço de produção de conhecimento. Proporcionando a articulação de saberes, devendo dar enfoque na importância da questão ambiental, levando os profissionais, a um maior compromisso com a causa ambiental.

Por considerar que as investigações envolvendo os seres humanos devem assegurar que seus direitos sejam protegidos, em consonância com a Resolução $\mathrm{N}^{\circ}$ 466/12 do Conselho Nacional da Saúde, este estudo adotou os princípios básicos da 
bioética: autonomia, beneficência, não maleficência, justiça e equidade (BRASIL, 2012).

\section{RESULTADOS E DISCUSSÕES \\ CARACTERIZAÇÃO DOS SUJEITOS}

Os sujeitos do estudo foram um ex-pescador A. M. M., 64 anos, casado, residente no município de Camocim, trabalhou na pesca artesanal e industrial durante 30 anos e o dono de uma pesqueira R. D. S., 50 anos, casado, residente na cidade de Camocim e está na atividade pesqueira há 28 anos, além da observação dos pescadores.

\section{RESGATE DA HISTORICIDADE DO TRABALHO}

O trabalho na pesca é milenar e remonta aos modos de produção de coletores e caçadores. Trata-se de um processo de trabalho, que atravessou, na antiguidade, modos de produção agrícola, escravista, feudal e que persiste até a contemporaneidade, nas diversas regiões do mundo e civilizações (HOSBSBAWM, 2000).

No Brasil, a pesca artesanal caracterizou-se como atividade econômica, a partir da falência da economia do café e do açúcar no Período colonial e da necessidade de se explorar outros meios, que não fossem a coleta extrativa e a caça continental. Posteriormente, reconhecidos pela importância geoestratégica, os trabalhadores da pesca afirmaram-se nos espaços litorâneos com a constituição das colônias de pesca (FREITAS; RODRIGUES, 2014).

Durante as entrevistas ao se resgatar a historicidade do trabalho, as mudanças ocorridas e o modo de produção, observou-se aspectos comuns nas falas, quando se trata dos recursos pesqueiros, como falam os entrevistados, a diversidade e a quantidade de peixes está a cada dia mais escassa:

\footnotetext{
Mudou, mudou para pior! Sim, porque de primeiro o peixe tinha com mais fartura, hoje está mais escasso (Dono da pesqueira).

Aí se mudou muito, isso mudou, a gente trabalhava sempre mais perto da costa na água de 40, 50, 60 quilômetros pra terra e tinha peixe com abundância. Depois para o final a gente tinha que ir para mares, águas mais fundas, mais frias, e mais distantes dos locais, por exemplo, pegando a longitude lá perto da região Caribeana ficando por acolá (Ex-Pescador).

O modo de produção melhorou, mas é que o cardume é que está ficando pouco (Dono da Pesqueira).
}

Esse fato também é apontado pelo Instituto Brasileiro do Meio Ambiente e dos Recursos Naturais Renováveis (2000), que em seu Relatório de Estatística da Pesca, 
mostrou que com a diminuição de alguns estoques pesqueiros, os pescadores compensam a situação indo cada vez mais longe, permanecendo mais tempo nos locais de pesca e menosprezando as condições adversas do meio.

$\mathrm{Na}$ pesca artesanal devido a pressão econômica a que os pescadores estão sujeitos, principalmente, ao baixo custo cobrado e a escassez dos cardumes, estes têm estendido cada vez mais suas jornadas de trabalho, tanto no que diz respeito ao tempo de trabalho, quanto à distancia percorrida para alcançar os cardumes (GARRONE NETO; CORDEIRO; HADDAD JÚNIOR, 2005).

Fotos 1 e 2: Pescadores na Beira Mar de Camocim, Ceará, 2014.
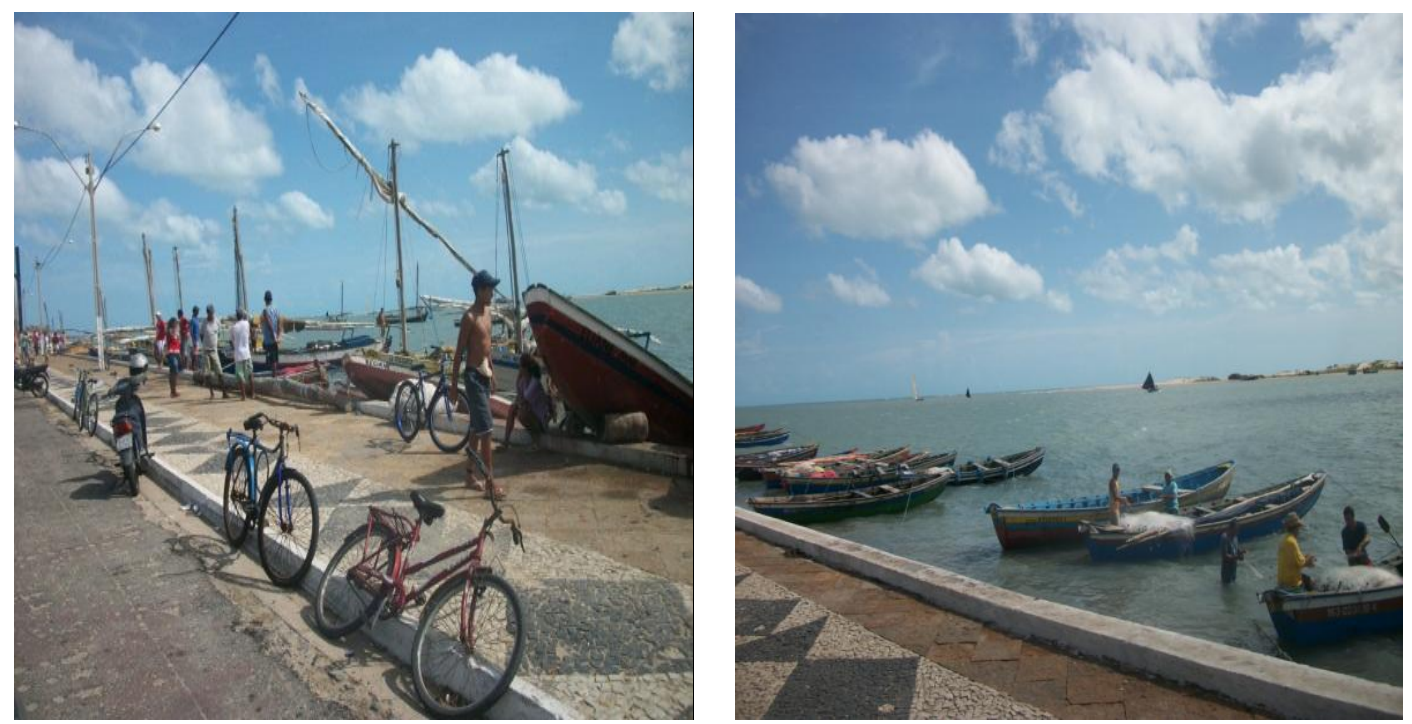

Fonte: Memorial Fotográfico (Acervo Pessoal dos Pesquisadores).

\section{DORES DA PESCA ARTESANAL: RELAÇÃO COM O MEIO AMBIENTE E SAÚDE}

A Classificação Nacional de Atividades Econômicas (2010) estabelece o Código A - 03 (Pesca e Aquicultura) com grau de risco médio. No caso de pescadores artesanais, em que dificilmente possuem relação de empregador/empregado, o uso de Equipamento de Proteção Individual (EPI) é total de responsabilidade dos próprios pescadores.

Já a Organização Internacional do Trabalho (2000) refere-se à pesca como uma das mais desgastantes e perigosas atividades desenvolvidas pelo homem. Estudos apontam para a fragilidade dos aspectos relacionados à segurança e saúde do trabalhador do setor da pesca (DOIMO et al, 2012). As atividades desenvolvidas na profissão do pescador artesanal e o meio ambiente no qual ele atua, têm relação com a 
exposição a riscos de desenvolvimento de algumas doenças ocupacionais, observa-se esta exposição no trecho abaixo:

Na pesca de canoa quase não tem proteção só roupa de frio, protetor, roupa de proteção ao sol (Ex-Pescador).

Estes trabalhadores vivenciam riscos ocupacionais, como a insolação e a desidratação, por passar horas a sol a pique. Ressalta-se que o contato excessivo sem proteção aos raios ultravioletas, pode levar a desidratação, insolação, até câncer de pele. Peharda et al (2007) afirmam que a exposição prolongada de pescadores e outros trabalhadores ao sol em seus ambientes de trabalho, se relaciona com doenças de pele causadas pela radiação ultravioleta. E alertam quanto à necessidade de prevenção primária dos trabalhadores, contra os efeitos dos raios ultravioletas, especialmente naqueles trabalhadores de pele menos pigmentada.

Já em um estudo de coorte realizado em 2008, com 9.419 pescadores da região da Andaluzia na Espanha, verificou-se que mais da metade dos pescadores, 54\% relataram lesões de pele relacionadas à exposição solar (NOVALBOS, 2008).

Outro ponto relevante é a existência de estresse ocupacional relacionado aos trabalhadores da pesca, decorrente das tensões associadas ao trabalho e à vida profissional que podem ser desencadeados por agentes estressores como ruído, iluminação, temperatura, higiene, disposição do espaço físico para o trabalho e fatores ambientais como clima (CARVALHO; SERAFIM, 2002). A narrativa abaixo relata alguns momentos estressantes, devido à exposição a perigos em alto mar:

Tem o momento difícil, quando a gente sai para se deslocar para ir para o alto mar, sempre vem a lembrança que a gente vai, mas não sabe se volta; porque trabalho tem risco, mas na pesca o maior risco são os naufrágios. Um prego no barco, a gente perde o rumo da volta, a comunicação, não tem socorro e outros mais; temporais, principalmente em áreas de grandes frentes frias, elas são altamente fatais (Ex-Pescador).

Na coleta das informações, também se observou que os profissionais da pesca, trabalham frequentemente com maquinário, motor, correia de motor, que são instrumentos do cotidiano do pescador e que produzem bastante ruído. Tais condições podem ocasionar perdas auditivas no pescador, pois como afirmam Axelsoson, Arvidsson e Jerson (2006), o confinamento em uma embarcação durante um longo período, e a exposição a níveis sonoros elevados, contribui para a incidência de Perda Auditiva Induzida por Ruído (PAIR). Além disso, existem outros fatores a que esta população está exposta, como a vibração local no braço e de corpo inteiro e a exposição 
prolongada ao monóxido de carbono, também podem trazer danos à audição do trabalhador da pesca.

Em relação ao instrumentos de trabalho utilizados observa-se a fala seguir:

O principal o material era linha nylon, no caso e anzol, né e mais algumas coisas chumbadas, e aí o sistema de isca, a sardinha na pesca. A principal pesca que eu me aperfeiçoei mais, era no camarão; aí ia vários os apetrechos eram muitos: cabo de aço, o nylon, polietileno para tecer. Para ter as redes, portos para substituir galões, umas armações que nós chamamos de cavalo, ferro e o sistema de tratamento do pescado, com vários ingredientes para deixar o pescado melhor (Ex-Pescador).

A fala descreve o esforço físico usado no trabalho do pescador artesanal, que segundo Dall'Oca (2004) a quantidade de vezes em que os pescadores empurram o barco, lançam e puxam a rede pode causar, além de cansaço físico, males e doenças dos ossos e coluna. Outro aspecto ressaltado das práticas insalubres de trabalho é a ocorrência de dermatoses na região das mãos devido à manipulação de pescado (peixes, crustáceos e moluscos) sem fazer uso de luvas. Ressalta-se que alguns pescadores sinalizaram que o uso de luvas atrapalha e, que os EPI não resistem a atividades da pesca.

Gann (2005) aponta que a profissão dos pescadores artesanais exige esforços físicos prolongados, e isso os torna sujeitos a ter lombalgia, mas o impacto dos fatores citados sobre cada trabalhador é diferente devido às variações individuais e as variações no mesmo sujeito ao longo do tempo.

Outro aspecto relacionado com a atividade ocupacional, que foi observado durante este estudo, foi o consumo de fumo e bebidas alcoólicas. Bezerra (2002) em um estudo realizado na região Norte do Brasil, demonstrou que os pescadores apresentam mais problemas de consumo de álcool e tabaco, que outros moradores do mesmo local. A maior parte desses problemas relaciona-se com a baixa remuneração e com as condições de trabalho oferecidas pela atividade.

A dura jornada de trabalho, inclui a exposição a fatores ambientais, como a temperatura, exposição a insetos hematófagos, o que torna a aguardente denominada de cachaça pelos pescadores, um instrumento rotineiro nas pescarias, pois é utilizada para a limpeza de ferimentos sofridos durante o exercício da atividade pesqueira, além de acalorar os pescadores (BEZERRA, 2002).

Figura 2: Dores da pesca artesanal: riscos ocupacionais a que o pescador está exposto, Camocim, Ceará, 2014. 


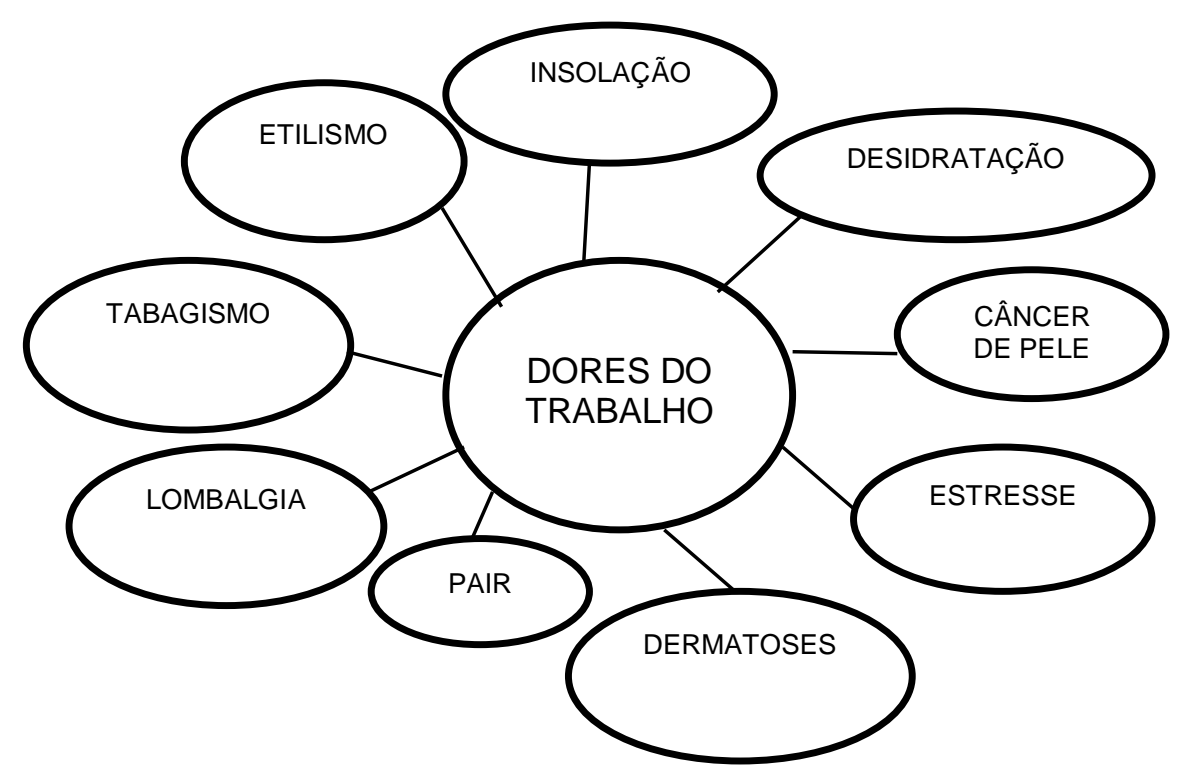

O meio ambiente do trabalho está sendo cada vez mais compreendido como um espaço para promoção da saúde e para o desenvolvimento de atividades preventivas de riscos, agravos e doenças (SILVA; MERCES; ARAÚJO, 2014). Desta forma, observouse que, as dores originadas pelo trabalho e ambiente se refletem em diversos aspectos da saúde, como o risco de desenvolvimento de doenças ocupacionais, conforme demonstrado na Figura 2. Esses reflexos na saúde e qualidade de vida desses trabalhadores, despertam a necessidade de políticas, ações e serviços de saúde específicos para esta população, pois quase sempre estes não tem acesso, por conta de políticas como a Estratégia Saúde da Família, dentre outras, não estarem disponíveis nos horários de folga dos pescadores e/ou as equipes da saúde não estarem preparados para acolher suas demandas e necessidades específicas.

Neste contexto, é preciso conhecer as condições, as situações de exposição, os efeitos específicos que produzem na saúde e na vida dos trabalhadores, para que as ações de intervenção e as medidas de proteção à saúde possam ser adequadamente planejadas, executadas e alcancem os resultados desejados (ARAÚJO; FARIAS, 2011).

\section{DELÍCIAS DA PESCA ARTESANAL: A SATISFAÇÃO DO FAZER E DO SER PESCADOR}

Neste estudo, podemos observar que, apesar das diversas condições precárias de trabalho, como o risco à saúde, condições insalubres a que os trabalhadores estão submetidos diariamente, está intrínseco na atividade do pescador, a satisfação pelo seu 
trabalho. Pois, a atividade pesqueira integra o pescador a natureza, e isso o faz desenvolver sentimentos como encantamento, satisfação, espontaneidade e, principalmente, liberdade (LIRA, 2010).

Verifica-se isso nas falas dos entrevistados:

Quando a gente está pescando, principalmente, quando têm boas pescarias, [a pesca] não é um trabalho é um dos melhores esportes que têm (Ex-Pescador).

Desde menino a gente de Camocim tem uma vocação para o mar, né! [...] mas eu fui trabalhar na pesca, porque era uma vocação de menino, fazia um barquinho pra andar puxando e aquilo vai ligando a gente com as coisas do mar (Dono da Pesqueira).

As falas dos sujeitos associam o trabalho a uma atividade esportiva ou de lazer, esta percepção demonstra a satisfação em ser pescador e no seu fazer cotidiano. Tal satisfação está relacionada a liberdade proporcionada na pesca e a sensação de prazer, além da proximidade com a profissão, desde o período da infância. Spector (2003) descreve que, a satisfação no trabalho é um elemento importante, pois reflete como um sujeito se sente, com relação ao trabalho de forma geral e em seus vários aspectos, estando relacionado a sua saúde, longevidade e qualidade de vida.

O Movimento dos Pescadores Artesanais (2012), aponta que a atividade pesqueira possui uma dinâmica singular, e é mais que uma profissão, é um modo de vida, em que o trabalho é livre e tem um regime autônomo e coletivo, carrega histórias, culturas passadas de geração para geração; evidencia as relações do pescador artesanal e seu modo de vida tradicional e de lidar com a natureza.

Outra delícia do trabalho observada e relatada, é o fato de que os recursos pesqueiros se configuram, como a principal fonte de renda dos sujeitos do estudo, que está atrelada a satisfação pessoal. Na Figura 3, observa-se uma síntese das delícias relacionadas ao trabalho na pesca artesanal:

Figura 3: Delícias da pesca artesanal, Camocim, Ceará, 2014.

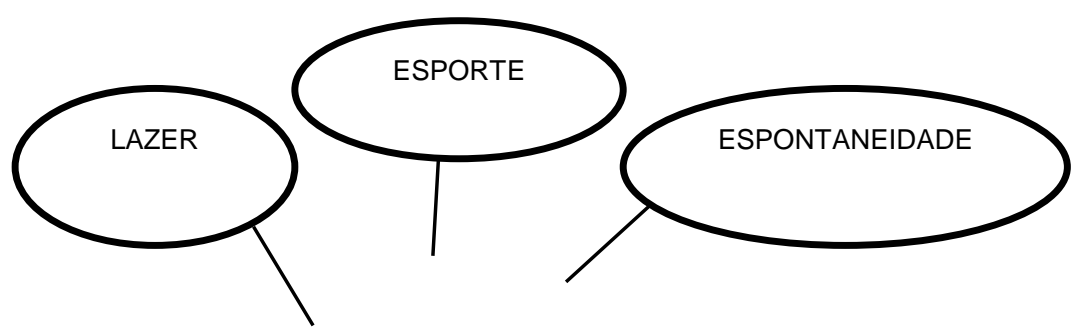




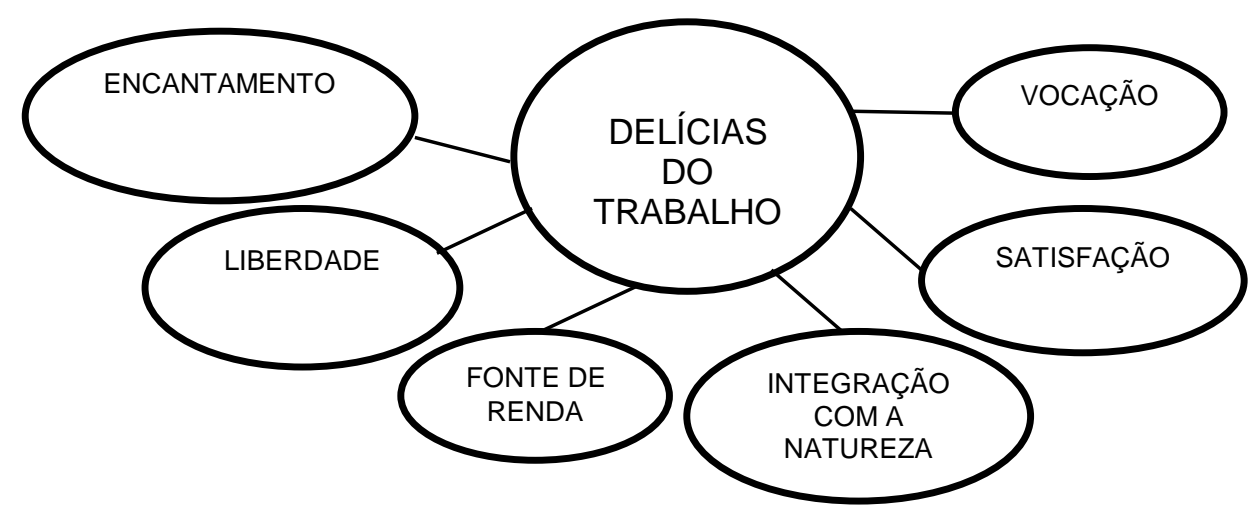

Vale destacar que, as delícias proporcionadas durante o desempenho de uma atividade laboral, contribuem de certo, com a qualidade de vida dos trabalhadores. $\mathrm{O}$ fato dos trabalhadores da pesca apontarem satisfação e prazer no trabalho, mesmo com os riscos, agravos e doenças desenvolvidas em seu labor, expressam de certo modo, algo relacionado a qualidade de vida.

Destarte, entendemos qualidade de vida, como a percepção do sujeito sobre a sua posição na vida, no contexto da cultura e dos sistemas de valores nos quais ele vive, e em relação a seus objetivos, expectativas, padrões e preocupações (RODRIGUEZ; ALVES, 2008). Nessa perspectiva, o trabalho tem um papel fundamental na inserção dos sujeitos no mundo, contribuindo para a formação de sua identidade, construção da subjetividade, permitindo que estes participem da vida social, elementos essenciais para a saúde (CODO, 1999).

\section{CONSIDERAÇÕES FINAIS}

A pesca artesanal está relacionada a aspectos geradores de satisfação no trabalho, bem como de determinantes de adoecimento, que podem estar relacionadas diretamente a função que o trabalhador exerce, aos instrumentos utilizados e sua interação com o meio ambiente.

As dores da pesca artesanal se relacionam aos riscos, agravos e doenças relacionadas ao trabalho, que estão presentes nas atividades pesqueiras, tais como: desidratação, insolação, doenças da pele causadas pelos raios ultravioletas, estresse ocupacional associado às tensões do trabalho e vida profissional, lombalgia, dermatoses, doenças nos ossos e/ou coluna, devido aos esforços físicos prolongados, PAIR por conta dos ruídos produzidos pelos maquinários utilizados, problemas com o consumo de álcool e tabaco, além da precariedade das condições de trabalho. 
Apesar das condições precárias de trabalho, observa-se também as delícias da atividade pesqueira, pois no mar o pescador sente-se autônomo, livre e protagoniza aventuras, que associam o trabalho com o prazer pessoal e a satisfação pelo contato com a natureza.

A Política Nacional de Saúde Integral das Populações do Campo, da Floresta e das Águas, representa o compromisso firmado entre o Estado Brasileiro com a saúde dessas populações. Pois, visa garantir o direito e o acesso à saúde pautado nos princípios fundamentais do Sistema Único de Saúde (SUS): equidade, universalidade e integralidade (BRASIL, 2013), necessitando avançar quanto à proteção sócio-sanitária dos trabalhadores da pesca.

No entanto, há necessidade de medidas de proteção aos trabalhadores, sendo necessário que se estabeleçam políticas públicas voltadas específicas para tais trabalhadores, visando reduzir os riscos e os danos causados à saúde, devido ao exercício da profissão e, que melhore a qualidade de vida destes (ALBUQUERQUE et al., 2012).

\section{REFERÊNCIAS}

ALBUQUERQUE, M.E.S.; MORAIS, R.S.; XIMENES, J.M.; MOURA, C.C.B.; FREITAS JÚNIOR, R.O.; XIMENES NETO, F.R.G.. Qualidade de vida no trabalho e riscos ocupacionais dos mototaxistas: um estudo de caso. Revista CPAQV - Centro de Pesquisas Avançadas em Qualidade de Vida. v. 4, n.3, 2012. p. 1-9.

ARAÚJO, T.M.; FARIAS, M.D. Transtornos mentais comuns entre trabalhadores da zona urbana de Feira de Santana-BA. Rev. Bras. Saúde Ocup. v. 36, n. 123, p. 25-39, 2011.

AXELSSON, A.; ARVIDSSON, I.; JERSON, T. Hearing in fishermen and coastguards. In: Salvi RJ, Henderson D, Hamernik RP. Basic and Applied Aspects of Noise-Induced Hearing Loss. NATO Science Series Life Sciences, 2006.

BAUM, M.; POVALUK, M. A Educação Ambiental nas Escolas Públicas Municipais de Rio Negrinho, SC. Saúde Meio Ambient. v. 1, n. 1, p 38- 52, 2012.

BEZERRA, B. Distúrbios psiquiátricos em pescadores da Amazônia. Jornal da Paulista. v. 168, p. 1-2, 2002.

BRASIL. Instituto Brasileiro do Meio Ambiente e dos Recursos Naturais Renováveis. Estatística da pesca 2000. Brasil - grandes regiões e unidades da federação.

Brasília: Instituto Brasileiro do Meio Ambiente e dos Recursos Naturais Renováveis, 2000. 
BRASIL. Ministério da Saúde. Promoção da saúde: carta de Otawa. Declaração de Adelaide Sunsvall e Santa de Bogotá. Brasília: Ministério da Saúde, 2001.

BRASIL. Classificação Nacional de Atividades Econômicas (CNAE). Comissão Nacional de Classificação. 2010. Disponível em: http://www.cnae.ibge.gov.br/. Acesso em 19 de set. de 2015.

BRASIL. Ministério da Pesca e Aquicultura. Pesca artesanal. 2011. Disponível em: http://www.mpa.gov.br/pescampa/artesanal. Acesso: 7 de dez. de 2014.

BRASIL. Instituto Brasileiro de Geografia e Estatística (IBGE). Cidades@: 2011. 2011b. Disponível em: http://www.ibge.com.br/cidadesat/topwindow.htm?1. Acesso em 12 de jul. de 2015.

BRASIL, Ministério da Saúde. Secretaria de Gestão Estratégica e Participativa. Política Nacional de Saúde Integral das Populações do Campo e da Floresta. 1 ed. Brasília: Editora do Ministério da Saúde, 2013.

BRASIL. Conselho Nacional de Saúde. Comissão Nacional de Ética em Pesquisa. Resolução no 466, de 12 de dezembro de 2012. Diretrizes e normas regulamentadoras de pesquisa envolvendo seres humanos. Brasília: Ministério da Saúde, 2012.

CASTELLANOS, P.L. Epidemiologia, saúde pública, situação de saúde e condições de vida: considerações conceituais. In: BARATA, R.C.B. (Org.). Condições de vida e saúde. Rio de Janeiro: Abrasco, 1997. p. 31-75.

CARVALHO, A.V.; SERAFIM, O.C.G. Administração de recursos humanos. v. II. São Paulo: Ed. Pioneira, 2002.

CEARÁ. Secretaria da Pesca e Aquicultura do Estado do Ceará. Relatório geral das ações de desenvolvimento da pesca (2011 - 2014). 2014. Disponível em http://www.spa.ce.gov.br/index.php/downloads\#. Acesso em 02 de maio de 2017.

CODO, W. Indivíduo, trabalho e sofrimento: uma abordagem interdisciplinar. $4^{\mathrm{a}}$ ed. Petrópolis (RJ): Vozes, 1999.

COMISSÃO NACIONAL SOBRE DETERMINANTES SOCIAIS DA SAÚDE (CNDSS). As causas sociais das iniquidades em saúde no Brasil. Rio de Janeiro: Editora Fiocruz, 2008.

DAHLGREN, G.; WHITEHEAD, M. Policies and strategies to promote social equity in health. Stockholm: Institute for Future Studies, 1991.

DALL'OCA, A.V. Aspectos sócio-econômicos, de Trabalho e de Saúde de pescadores do Mato Grosso do Sul. 2004. 52 f. Dissertação. (Mestrado em Saúde Coletiva) - Universidade Federal do Mato Grosso do Sul, Campo Grande. 
DOIMO, R.A.; BARRELLA, W.; MELLO, A.L.R.; RAMIRES, M.. Equipamentos e doenças laborais dos pescadores artesanais da estação ecológica Juréia-Itatins (SP).

UNISANTA Law and Social Science. v. 1, n. 1, p. 7-11, 2012.

FREITAS M.B.; RODRIGUES, S.C. A. As consequências do processo de desterritorialização da pesca artesanal na Baía de Sepetiba (RJ, Brasil): um olhar sobre as questões de saúde do trabalhador e o ambiente. Ciência \& Saúde Coletiva, v. 19, n. 10, p. 4001-4009, 2014.

GANN, N. Ortopedia: Guia de consulta rápida para fisioterapia. Série Physio/Fisioterapia Prática. Editora Guanabara Koogan: Rio de Janeiro, 2005.

GARRONE NETO, D.; CORDEIRO, R.C.; HADDAD JÚNIOR, V.. Acidentes de trabalho em pescadores artesanais da região do Médio Rio Araguaia, Tocantins, Brasil. Cad. Saúde Pública. v. 21, n. 3, p. 795-803, 2005.

HOSBSBAWM, E.J. Os trabalhadores: estudo sob a história do operariado. São Paulo: Paz e Terra, 2000.

LIRA, F.F.M. Entre Artífice e Operário: Discursos Sobre o Trabalho do Pescador Artesanal. 2010. 266 f. Dissertação. (Mestrado em Psicologia) - Universidade de Fortaleza, Fortaleza, Ceará.

MINAYO, M.C.S. O desafio do conhecimento: pesquisa qualitativa em saúde. 11. ed. São Paulo: Hucitec, 2014.

MONTEIRO, S.V. A pesca artesanal nas praias urbanas de Natal: trabalho, lazer e práticas culturais. I Reunião Equatorial de Antropologia e x Reunião de Antropólogos Norte-Nordeste (Anais). Aracaju: UFS, 2007.

MORADILIO, E.F.; OKI, M.C.M. Educação ambiental na universidade: construindo possibilidades. Quim Nova. v. 27, n. 2, p. 332-6, 2004.

MOVIMENTO DOS PESCADORES ARTESANAIS (MPP). Cartilha Movimento Pescadores e Pescadoras Artesanais. Bahia. 2012. Disponível em http://cppnorte.wordpress.com/documentos/. Acesso em 30 de abr. de 2017.

NOVALBOS, J. Occupational health in Andalusian fisheries sector. Marine Policy. v. 58 , n. 2, p. 141-3, 2008.

ORGANIZAÇÃO INTERNACIONAL DO TRABALHO (OIT). Anuário de estatísticas do trabalho. Brasília: Organização Internacional do Trabalho, 2000.

PEHARDA, V.; GRUBER, F.; KASTELAN, M.; MASSARI, L.P.; SAFTIĆ, M.;

CABRIJAN, L.; ZAMOLO, G. Occupational skin diseases caused by solar radiation. Coll Antropol. v. 31, n (supl1), p. 87-90, 2007.

RODRIGUEZ, M.V.R.; ALVES, J.B. Qualidade de vida dos professores: um bem para todos. IV Congresso Nacional de Excelência em Gestão (Anais). Niterói (RJ): UFF, 2008. p. 1-23. 2. 
SILVA, B.S.M.; MERCES, M.C.; ARAÚJO, T.M. Interface entre saúde, ambiente e trabalho na ótica da sustentabilidade. Rev Epidemiol Control Infect. v. 4, n. 2, p. 165$170,2014$.

SPECTOR, P.E. Psicologia nas Organizações. Editora Saraiva, 2003.

VARGAS, L.A.; OLIVEIRA, T.F.V.R. Saúde, meio ambiente e risco ambiental: um desafio para a prática profissional do enfermeiro. Enferm UERJ. v. 15, n. 2, p.451-5, 2007. 